\title{
O “cinema” cantado dos Maxakali
}

\author{
The sung "cinema" of the Maxakali
}

\section{RESUMO:}

Dr. Charles Antônio de Paula Bicalho Universidade do Estado de Minas Gerais (UEMG) - Unidade Cláudio

E-mail: charlesbicalho@gmail.com ORCID: https://orcid.org/0000-0002-4281-2141

Este estudo trata de aspectos da imagem na arte verbal dos Maxakali ou Tikmû'ûn, povo indígena que habita Minas Gerais. Com população em torno de dois mil indivíduos, os Maxakali falam sua língua ancestral, o Maxakali, do tronco linguístico Macro-Gê. Seus cantos rituais, chamados yãmîy, são pródigos na apresentação de imagens que descrevem elementos de seu mundo terreno e espiritual. Objetos, personagens, cenários, cenas e diálogos que compõem suas narrativas tradicionais emergem condensados em seus cantos durante seus rituais yãmîyxop. Compostos segundo um método ideogrâmico e emitidos em certa sequência, os cantos rituais yãmîy dão aos rituais maxakalis um caráter protocinematográfico, uma vez que evocam imagens sequenciais para narrar. Com foco no filme Konãgxeka: o Dilúvio Maxakali (2016), uma realização da produtora Pajé Filmes com os Maxakali, baseada em história tradicional deste povo, procura-se demonstrar como a lógica do ritual auxilia na estruturação da obra audiovisual.

Palavras-chave: Imagem. Cinema. Maxakali.

\section{ABSTRACT:}

This study focus on image aspects in the verbal art of the indigenous people Maxakali or Tikmû'ûn. With a population of around two thousand individuals living in three territories in the state of Minas Gerais, Brazil, the Maxakali speak their ancestral language, the Maxakali, from the Macro-Gê linguistic stem. They are lavish in presenting images in their ritual chants, which depict elements of their real and spiritual world. Objects, characters, scenarios, situations, scenes and dialogues that make up their traditional narratives emerge condensed into their songs during their rituals.

BICALHO, Charles Antônio de Paula. o "cinema" cantado dos Maxakali PóS:Revista do Programa de Pós-graduação em Artes da EBA/UFMG. v.9, n. 18: nov.2019 Disponível em < https://eba.ufmg.br/revistapos $>$

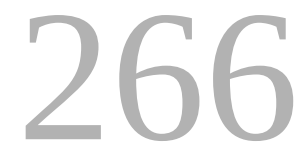


Compound according to an ideogramic method and emitted in a certain sequence, the ritual chants, called yãmîy, give the Maxakali yãmîyxop rituals a proto-cinematographic character, since they evoke sequential images to narrate. Focusing the movie Konãgxeka: the Maxakali Flood (2016), a production by Pajé Filmes with the Maxakali people, based on a traditional story of this people, we seek to demonstrate how the logic of the ritual helps in structuring the audiovisual work.

Keywords: Image. Cinema. Maxakali.

Artigo recebido em: 03/06/2019 Artigo aceito em: 13/08/2019

BICALHO, Charles Antônio de Paula. o "cinema" cantado dos Maxakali

PóS:Revista do Programa de Pós-graduação em Artes da EBA/UFMG. v.9, n.18: nov.2019

Disponível em < https://eba.ufmg.br/revistapos $>$ 
"Alguns componentes da máquina cinemática estão em uso há muitos séculos: formas de projeção, imagens em movimento, viagens imóveis e iluminações visionárias."

(Jonathan Crary)

"A imagem não é uma exclusividade do visível. Há um visível que não produz imagem, há imagens que estão todas em palavras."

(Jacques Rancière)

Em Pré-cinemas e pós-cinemas (1997), Arlindo Machado afirma que "pode haver uma representação mais eloquente do movimento, da duração, do trabalho modelador do tempo e do sincronismo audiovisual nas formas pré e pós-cinematográficas do que nos exemplos 'oficiais' da performance cinematográfica" (p. 9). E, mais à frente, continua:

Quanto mais os historiadores se afundam na história do cinema, na tentativa de desenterrar o primeiro ancestral, mais eles são remetidos para trás, até os mitos e ritos dos primórdios. Qualquer marco cronológico que possam eleger como inaugural será sempre arbitrário, pois o desejo e a procura do cinema são tão velhos quanto a civilização de que somos filhos (p. 14).

Acreditamos oferecer aqui algumas pistas daquilo que Machado ainda julga "reprimido na grande maioria dos discursos históricos sobre o cinema". Ou seja, "o devir do mundo dos sonhos, o afloramento do fantasma, a emergência do imaginário e o que ele tem de gratuito, excêntrico e desejante, tudo isso, enfim, que constitui o motor mesmo do movimento invisível que conduz ao cinema" (MACHADO, 1997, p. 15). Dito de outro modo, esperamos demonstrar como o ritual tradicional de povos como os maxakalis de algum modo já pode trazer um certo impulso em direção ao cinema e seus mecanismo de associação da imagem e seu movimento ao som.

\section{Os Maxakali, seus yãmîy e seus yãmîyxop}

Os Maxakali ou Tikmû'ûn ${ }^{1}$ são um povo indígena de aproximadamente dois mil indivíduos que vivem em três territórios no estado de Minas Gerais. Suas reservas se localizam nos municípios de Bertópolis e Santa Helena de Minas, no Vale do Mucuri, e no município de Ladainha, próximo à cidade de Teófilo Otoni.

BICALHO, Charles Antônio de Paula. o "cinema" cantado dos Maxakali

PóS:Revista do Programa de Pós-graduação em Artes da EBA/UFMG. v.9, n.18: nov.2019

Disponível em < https://eba.ufmg.br/revistapos $>$

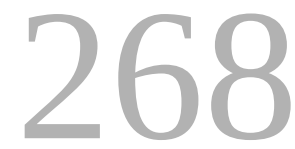


Povo bilíngue, os maxakalis falam sua língua ancestral, o Maxakali, e o português. As crianças só iniciam o aprendizado sistemático da língua portuguesa por volta dos 10 anos de idade, após sedimentada a língua maxakali, como estratégia de preservação linguística e cultural.

A religião Maxakali é baseada em seus espíritos yãmîy e na realização de seus rituais yãmîyxop. Animais e outros elementos da natureza, além de espíritos de pessoas falecidas, tornam-se yãmîy para os Maxakali. Outros objetos, inclusive exógenos, como o avião ou helicóptero, futebol, sanfona e até o próprio "homem branco", acabaram por se tornar yãmîy no complexo de rituais yãmîyxop.

Canto, dança, culinária, figurino, bem como outros estímulos sensoriais, são acessados na realização dos rituais yãmîyxop para homenagear e se relacionar com os espíritos yãmîy. Os Maxakali nomeiam também seus cantos de yãmîy, pois ser espírito pressupõe a existência de canto, ou cantos, que o corporifique ou represente (ver POPOVICH, 1976; ALVARES, 1986; BICALHO, 2010; TUGNY, 2011). Portanto, a palavra nomeia tanto o espírito quanto o canto. A partícula xop de yãmîyxop tem o sentido de "grupo ou reunião". Os rituais, então, são reuniões de espíritos e humanos, bem como um momento em que uma quantidade de cantos, entre outros elementos, são agenciados para a realização do encontro entre o mundo terreno e o mundo dos espíritos.

\section{Ideogramaxakali: canto e imagem e a montagem literária}

Há uma categoria de cantos yãmîy que Bicalho (2007a) analisa enquanto gênero poético e reconhece um modo ideogrâmico de composição, ao estilo do imagismo do poeta norteamericano Ezra Pound, que, em sua prática e teoria, faz uma associação ao ideograma chinês e japonês e, consequentemente, à poesia oriental. Tal associação é retomada depois pelo poeta e teórico concretista Haroldo de Campos (1994). É notória também a associação, pelo viés do ideograma, que o cineasta russo Serguei Eisenstein (2002) faz com relação à linguagem cinematográfica.

BICALHO, Charles Antônio de Paula. o "cinema" cantado dos Maxakali

PóS:Revista do Programa de Pós-graduação em Artes da EBA/UFMG. v.9, n.18: nov.2019

Disponível em < https://eba.ufmg.br/revistapos $>$

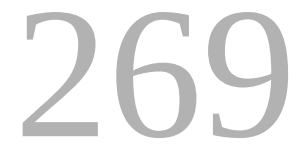


Como exemplificação, reproduzimos de Bicalho (2007b) a "Canção do martin-pescador pequeno", presente no Livro de Cantos Rituais Maxakali (2004), de autoria indígena:

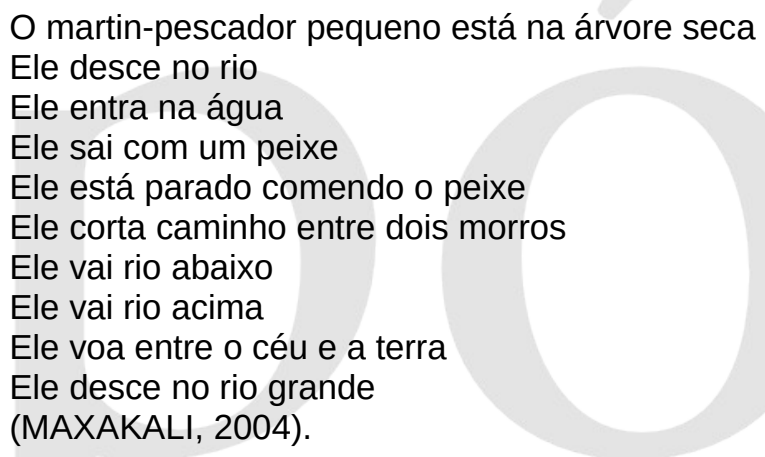

Cada verso do canto-poema maxakali pode ser visto como a descrição de uma ação, como se o poema fosse o roteiro sintético de uma cena. "Do nosso ponto de vista, estas são as frases de montagem. Listas de planos" (2002, p. 38), escreve o cineasta russo Serguei Eisenstein sobre o haicai, um gênero de poesia japonesa. No poema maxakali, é como se cada verso fosse a tomada de uma ação na composição da cena de um filme: entre uma ação e outra, há um corte (o final do verso). Como se cada verso fosse um plano. No entanto, Eisenstein não menciona que os versos no haicai apresentam ações. De fato, no gênero poético japonês, muitas vezes o verso apenas apresenta uma imagem, como uma paisagem, uma situação, ou mesmo um sentimento ou sensação, sem necessariamente algo acontecer ali. A ação pode aparecer em verso subsequente, ou simplesmente não aparecer, e o poema apenas uma descrição ou revelação. E é por esse viés, o da descrição, que enxergamos aqui uma analogia. Os cantos maxakalis são igualmente descritivos, sejam de ações, de situações, sejam de outros aspectos (há cantos que trazem apenas diálogos, por exemplo). Eisenstein, efetivamente, enfatiza que a escrita japonesa ou ideograma é, "de qualquer modo, nascido da conjugação dupla do descritivo como método" (EISENSTEIN, 2002. p. 38). E reconhece que ele se repete na pintura tradicional do Japão: "exatamente o mesmo método (em seu aspecto descritivo) age também nos mais perfeitos exemplos da arte pictórica japonesa" (Ibidem). Por nosso turno, enfatizamos aqui a analogia existente entre ambos os métodos (o japonês ou ideogramático e o maxakali ou indígena) na apresentação de uma relação entre os planos para a construção do sentido ou conceito, e não necessariamente na apresentação de uma ação nos ditos "planos" ou versos.

BICALHO, Charles Antônio de Paula. o "cinema" cantado dos Maxakali

PóS:Revista do Programa de Pós-graduação em Artes da EBA/UFMG. v.9, n.18: nov.2019

Disponível em < https://eba.ufmg.br/revistapos $>$

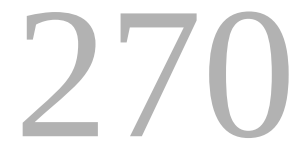


A antropóloga Bruna Franchetto (2012) refere-se à impressão cinematográfica parecida, percebida sobre seu trabalho de tradução de cantos ameríndios brasileiros. São "eventos em primeiro plano das cenas de fundo" (p. 41). A analogia com a linguagem cinematográfica é reforçada quando ela acrescenta: "cena em pinceladas, fotogramas, que deixam intuir uma estória sempre presente na memória" (p. 46-7).

Já o francês Claude Lévi-Strauss, em "A eficácia simbólica", ao analisar a estilística de um canto xamanístico dos índios Cuna, do Panamá, chama a atenção para algo parecido, usado como recurso de memorização. Ao tratar das descrições minuciosas de determinadas situações que se repetem no poema, ele escreve: "é como se fossem, dir-se-ia, filmados 'em câmara lenta". Enfatizamos aqui não a "câmara lenta", mas o "como se fossem (...) filmados". Lévi-Strauss não esmiuça em seu texto o que exatamente no canto indígena o remete à lógica da filmagem. Talvez o fato de o canto listar versos que apresentam um conteúdo facilmente "visualizável" na mente. Ou talvez o fato de o canto apresentar explicitamente uma sequência de ações facilmente imagináveis. O foco da análise do antropólogo, todavia, não é a associação com a linguagem cinematográfica. Tal passagem de sua obra é utilizada aqui como pretexto para percebermos algo da semelhança imagético-sequencial no modo de composição dos cantos indígenas. Transcrevemos abaixo o canto mencionado por Lévi-Strauss para que se possa comparar com o canto maxakali exposto acima:

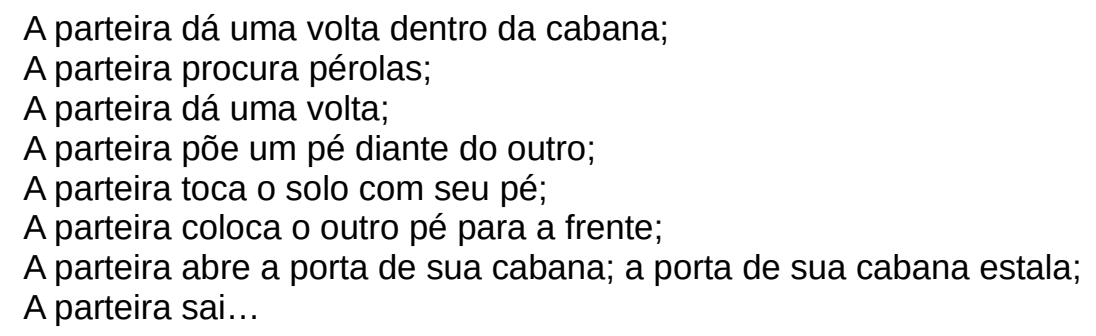

Mas existe também outra categoria de cantos yãmîy que Bicalho $(2018,2010)$ demonstra ser pródiga na fixação ou congelamento de certos elementos de suas histórias tradicionais ou mitos. Assim como uma fotografia ou pintura está para uma narrativa ou um acontecimento, os cantos yãmîy dos Maxakali estariam para suas histórias.

BICALHO, Charles Antônio de Paula. o "cinema" cantado dos Maxakali PóS:Revista do Programa de Pós-graduação em Artes da EBA/UFMG. v.9, n.18: nov.2019 Disponível em < https://eba.ufmg.br/revistapos $>$ 
Cotejando as narrativas com os cantos até agora traduzidos (...), verificamos uma relação intertextual em que alguns cantos entoados nos yãmîyxop maxakali funcionam como construções imagéticas de cenas, situações, personagens, diálogos, dentre outros aspectos presentes nas suas histórias (BICALHO, 2018, p. 92).

Como comprova Tugny (2011), "os cantos yãmîyxop reproduzem a experiência e a visão de algo que se passa 'aqui' na aldeia, e alhures, onde os espíritos podem se postar durante o trabalho dos cantos" (p. 3).

Em âmbito mais amplo, que engloba práticas literárias de outros povos indígenas, Bicalho reforça a argumentação com o antropólogo Lévi-Strauss, relido pelo poeta Octávio Paz, e pelo antropólogo brasileiro Viveiros de Castro, este último abordando o caso dos índios Araweté:

Talvez possamos associar tais cantos-yãmîy aos mitemas, na acepção que Lévi-Strauss dá a esse termo, que é posteriormente reelaborado por Otávio Paz (1970): 'frases ou sentenças mínimas que, por causa de sua posição no contexto, descrevem uma importante relação entre diferentes aspectos, incidentes, e personagens da história' (p. 27). Vê-se que os cantos Maxakali, à primeira vista tão lacônicos e sintéticos, atravessariam as narrativas Maxakali numa relação claramente intertextual com a mitologia, esse 'conjunto virtual' de que fala Viveiros de Castro (1986) quanto à arte verbal dos Araweté: 'A mitologia Araweté parece operar como um conjunto virtual que subjaz, na função de contexto, à proliferação cotidiana dos cantos xamanísticos (p. 41) (BICALHO, 2018, p. 100-101).

Tais cantos yãmîy, dessa maneira, quando emitidos nos rituais yãmîyxop, recontam, de modo cantado e bastante imagético, as histórias tradicionais dos Maxakali. Uma vez que toda a comunidade participante do ritual é conhecedora das histórias tradicionais a que os cantos se referem, a cantoria ritualística se configura num modo de reacessar tais histórias, fragmentariamente.

\section{Do "cinema" cantado ao cinema digital}

Em 2016, depois de vários filmes documentários, a produtora audiovisual Pajé Filmes, com sede na cidade de Belo Horizonte desde 2008, deu início à produção de filmes de animação com os Maxakali.

BICALHO, Charles Antônio de Paula. o "cinema" cantado dos Maxakali

PóS:Revista do Programa de Pós-graduação em Artes da EBA/UFMG. v.9, n.18: nov.2019

Disponível em < https://eba.ufmg.br/revistapos $>$

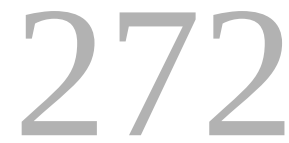


No filme Konãgxeka: o Dilúvio Maxakali $(2016)^{2}$, os cantos yãmîy foram tomados como guias, perfazendo uma espécie de roteiro cantado sintético que serviu de base para a produção. O roteiro do filme é baseado em história tradicional maxakali, em que um pajé e sua esposa encontram uma lontra no rio e estabelecem com ela uma parceria na pescaria: o animal os ajuda a localizar onde os peixes estão e o casal, após conseguir recolher os peixes com uma rede, alimenta o animal com os maiores peixes. A sinopse do filme complementa: Konãgxeka, na língua indígena maxakali, significa "água grande". Trata-se da versão maxakali da história do dilúvio. Como um castigo, por causa do egoísmo e da ganância dos homens, os espíritos yãmîy enviam a "grande água".

Por meio de pesquisa, foram coletados, registrados e traduzidos os yãmîy que compõem a sequência de cantos do ritual correspondente à história Konãgxeka na tradição maxakali. E foi esse acervo de cantos (transcriados para a língua portuguesa em parceira com Isael e Sueli Maxakali) que serviu também de trilha musical para o filme em questão.

Assim, o primeiro canto surge na abertura do filme:
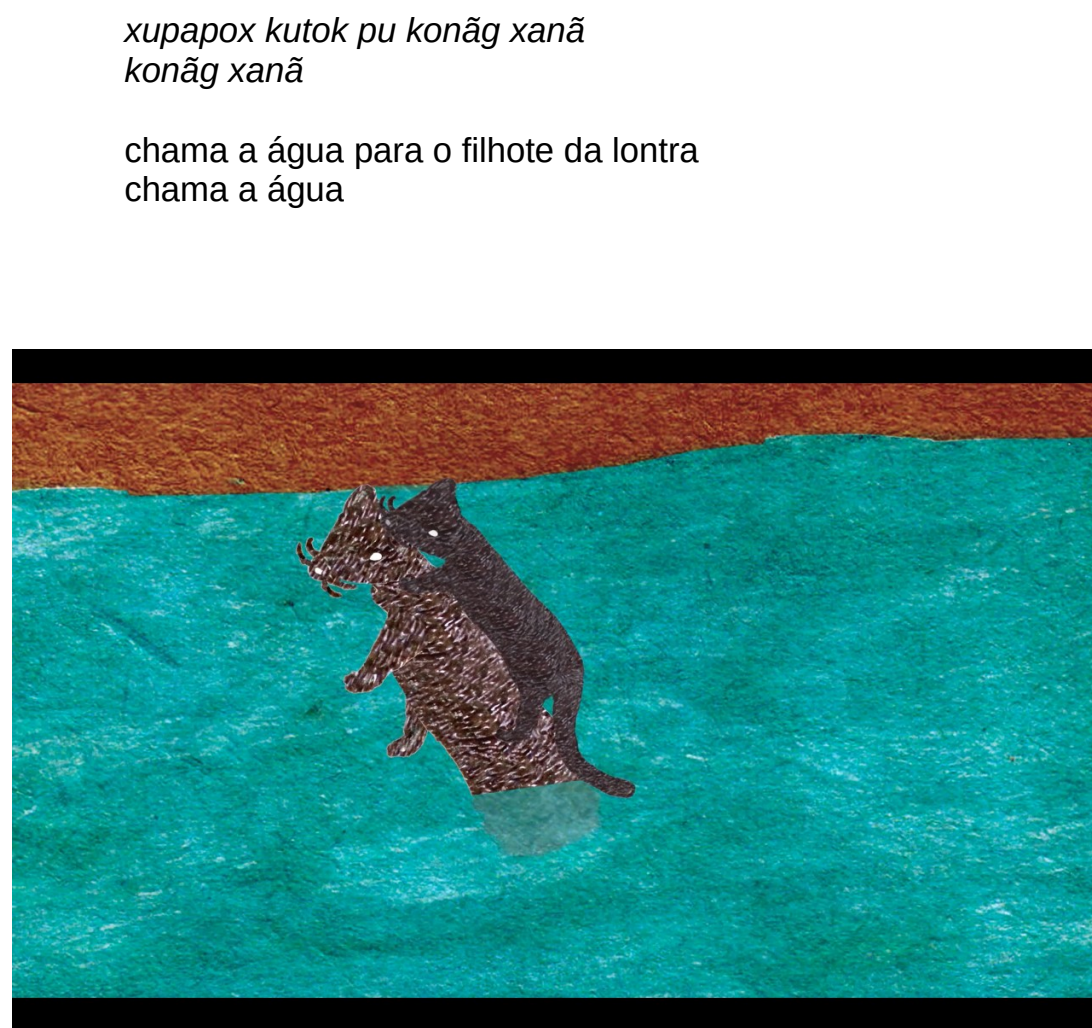

Figura 1 - Frame de Konãgxeka: o Dilúvio Maxakali - 2016 Fonte: Pajé Filmes.

BICALHO, Charles Antônio de Paula. o "cinema" cantado dos Maxakali

PóS:Revista do Programa de Pós-graduação em Artes da EBA/UFMG. v.9, n.18: nov.2019

Disponível em < https://eba.ufmg.br/revistapos $>$ 
Este canto situa o participante do ritual maxakali no ambiente que serve de hábitat para o animal personagem da história. Não à toa, foi utilizado na abertura do filme para sonorizar um plano de situação inaugural da história.

O segundo canto surge no filme em plano que continua a contextualizar o aparecimento do personagem animal:

xupapox xex mûn yõg

kuk yãnãm xex mõyãnãm nã mi

(KONÃGXEKA, 2016, 01:05)

é da lontra

a água que brilha

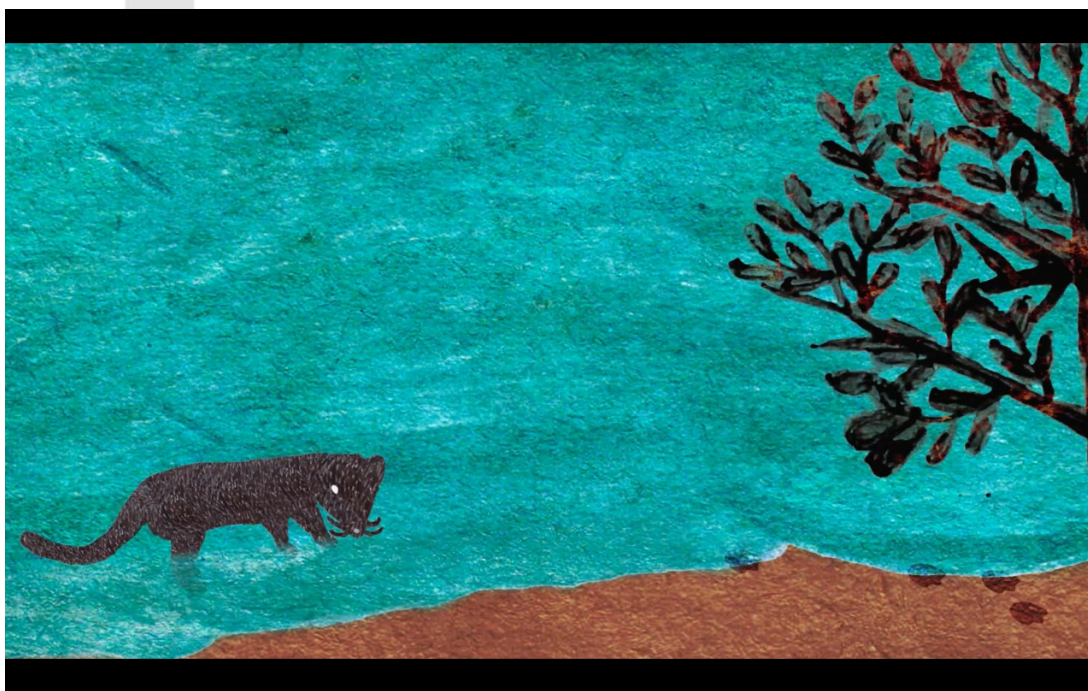

Figura 2 - Frame de Konãgxeka: o Dilúvio Maxakali - 2016

Fonte: Pajé Filmes.

O terceiro canto se refere ao momento do clímax do filme quando ocorre o cataclismo que dá nome à película. Suas palavras se resumem a descrever, de modo minimalista, a situação de um personagem que se encontra sentado quando tem início a grande chuva:

tex xeka pu yõg îyûm

tex xeka pu yõg îyûm

(KONÃGXEKA, 2016, 04:05)

embaixo da grande chuva me assento

embaixo da grande chuva me assento

BICALHO, Charles Antônio de Paula. o "cinema" cantado dos Maxakali

PóS:Revista do Programa de Pós-graduação em Artes da EBA/UFMG. v.9, n.18: nov.2019

Disponível em < https://eba.ufmg.br/revistapos $>$

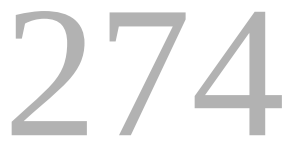




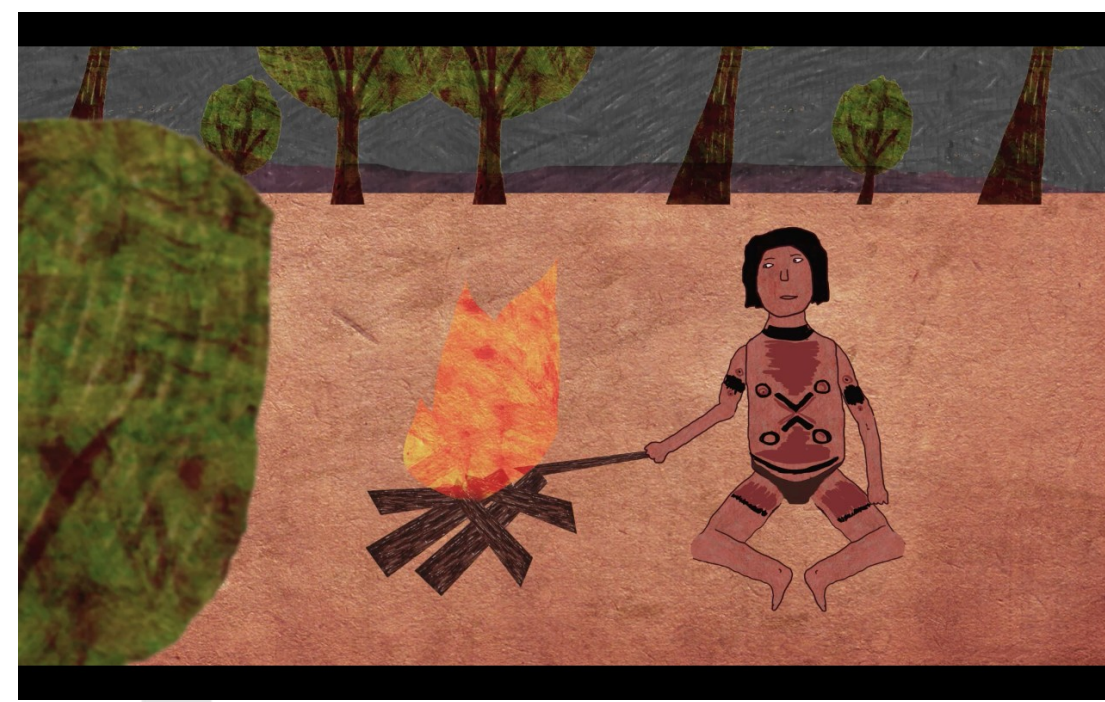

Figura 3 - Frame de Konãgxeka: o Dilúvio Maxakali - 2016

Fonte: Pajé Filmes.

O quarto canto se apresenta quando, após o dilúvio, dois espíritos yãmîy de abelha surgem para libertar o personagem ainda preso dentro de sua "arca", um tronco de árvore oco em que ele se escondera para se salvar da enchente, lacrando a sua entrada com couro de veado e lama:

\author{
xanãmok xex õm mõy \\ yãmîy yîmap \\ xanãmok xex õm mõy \\ yãmîy yîmap \\ pi a ãpata xi pi a ãmtox \\ ig pu ma tu nãy nûy igxut \\ (KONÃGXEKA, 2016, 06:30) \\ a abelha grande voa \\ o espírito esvoaça \\ a abelha grande voa \\ o espírito esvoaça \\ "Onde está seu pé e sua cabeça? \\ Pra gente poder tirar você"
}

BICALHO, Charles Antônio de Paula. o "cinema" cantado dos Maxakali

PóS:Revista do Programa de Pós-graduação em Artes da EBA/UFMG. v.9, n.18: nov.2019

Disponível em < https://eba.ufmg.br/revistapos $>$ 


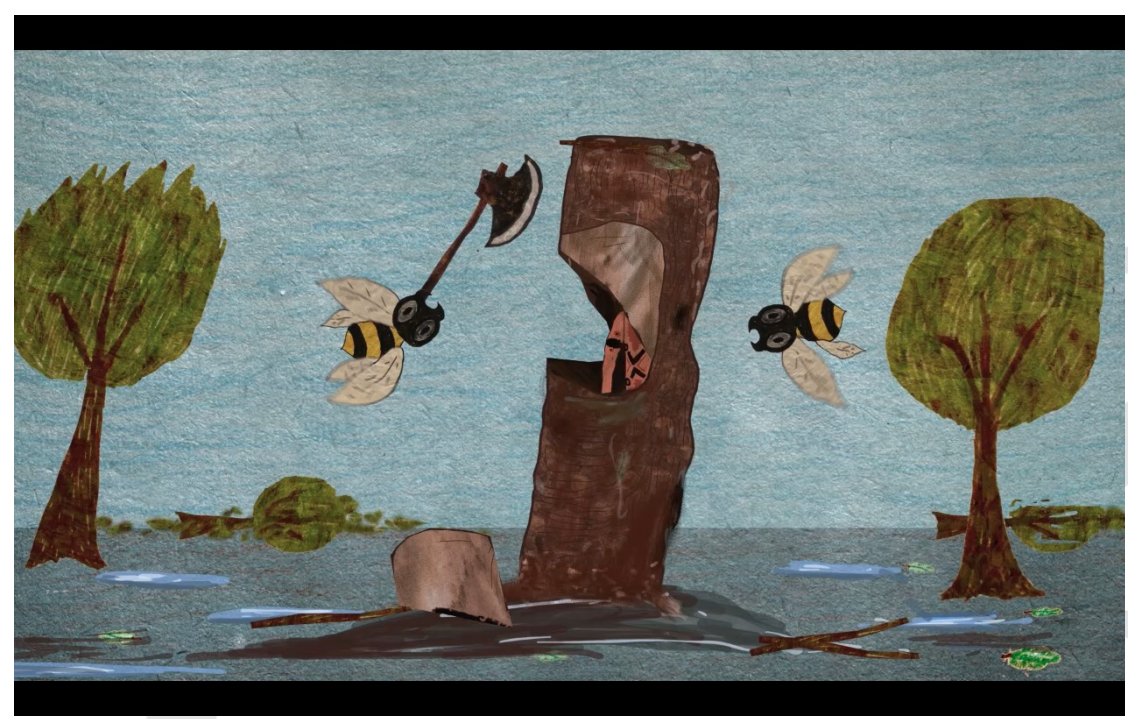

Figura 4 - Frame de Konãgxeka: o Dilúvio Maxakali - 2016

Fonte: Pajé Filmes

Esse canto contém a fala dos espíritos em questão, que dialogam com o personagem preso dentro do tronco, perguntando onde exatamente se localizavam os pés e a cabeça do índio na extensão do tronco, para que os espíritos soubessem onde bater o machado para cortar a madeira sem atingir o corpo do sobrevivente lá dentro.

O quinto canto surge no momento em que o personagem, agora liberto do tronco de árvore, tem de acasalar com uma fêmea de macaco, como fora determinado pelos espíritos yãmîy que o libertaram:

$$
\begin{aligned}
& \text { nêyê yêyê } \\
& \text { kuyõg te yõg îg mîy } \\
& \text { kuyõg te yõg îg mîy } \\
& \text { yêyê yêyê. } \\
& \text { ãyõg te yõg îg mîy } \\
& \text { ãyõg te yõg îg mîy } \\
& \text { yêyê yêyê } \\
& \text { pamak te yõg îg mîy } \\
& \text { pamak te yõg îg mîy } \\
& \text { yêyê yêyê } \\
& \text { kãyã te yõg îg mîy } \\
& \text { kãyã te yõg îg mîy } \\
& \text { yêyê yêyê } \\
& \text { topa te yõg îg mîy } \\
& \text { topa te yõg îg mîy } \\
& \text { yêyê yêyê }
\end{aligned}
$$

BICALHO, Charles Antônio de Paula. o "cinema" cantado dos Maxakali

PóS:Revista do Programa de Pós-graduação em Artes da EBA/UFMG. v.9, n.18: nov.2019

Disponível em < https://eba.ufmg.br/revistapos $>$ 
(KONÃGXEKA, 2016, 07:10)

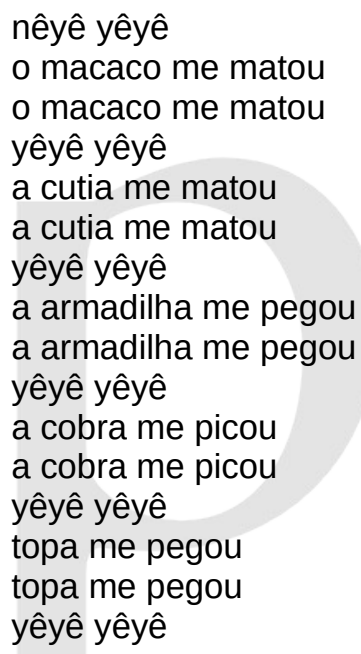

Tal canto prenuncia a sequência de três acasalamentos que o sobrevivente realizará em busca da parceira que lhe proporcionará o filho humano ideal ao repovoamento do mundo: primeiro, a macaca; segundo, a porca do mato; terceiro, a corsa.

O sexto canto segue após o malfadado nascimento de uma cria animal e não humana com a macaca. Após o sacrifício do filhote, o índio continua sua busca, até encontrar a porca. canto correspondente é uma síntese imagética do animal em seu hábitat.

xamup õm yîxux nã mi

xamup õm yîxux nã $m i$

(KONÃGXEKA, 2016, 08:15)

porco no mato camuflado

porco no mato camuflado

BICALHO, Charles Antônio de Paula. o "cinema" cantado dos Maxakali

PóS:Revista do Programa de Pós-graduação em Artes da EBA/UFMG. v.9, n.18: nov.2019

Disponível em < https://eba.ufmg.br/revistapos $>$ 


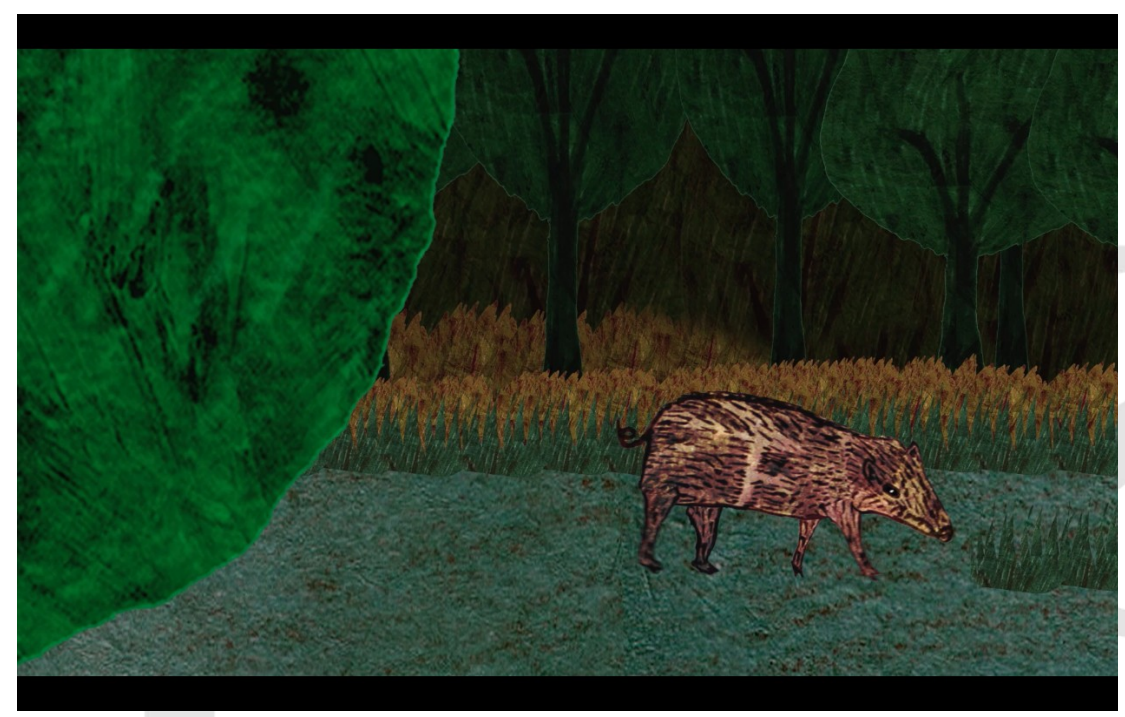

Figura 5 - Frame de Konãgxeka: o Dilúvio Maxakali - 2016 Fonte: Pajé Filmes.

O sétimo canto na sequência descreve a visão que o personagem tem quando do primeiro encontro com a corsa:

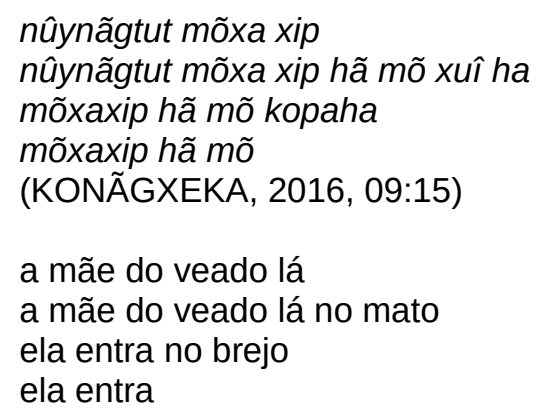

O oitavo e último canto, que se encontra nos créditos finais do filme, refere-se ao espírito que narra a história do dilúvio em questão. Sabemos que, na tradição religiosa maxakali, os espíritos yãmîy, geralmente representados por elementos da natureza (sobretudo os animais), são os narradores de suas histórias e, portanto, de seus rituais:

\author{
mõymõka tap õm \\ pemi ãxup nûy \\ mõymõka tap õm \\ pemi ãxup nûy \\ o gavião preto \\ voa alto \\ o gavião preto \\ voa alto
}

BICALHO, Charles Antônio de Paula. o "cinema" cantado dos Maxakali

PóS:Revista do Programa de Pós-graduação em Artes da EBA/UFMG. v.9, n. 18: nov.2019

Disponível em < https://eba.ufmg.br/revistapos $>$ 
Como de praxe, o canto em sua síntese, limita-se a descrever o voo da ave.

Torna-se fácil lembrar da narrativa em sua completude quando são facilmente lembradas as sequências de suas ações mais significativas, sintetizadas em cantos que são sabidos de cor. O mesmo princípio foi aplicado à produção do filme Konãgxeka.

\section{Diagrama e cronofotografia: fixação e êxtase}

Os cantos yãmîy dos Maxakali parecem funcionar, pois, como diagramas para suas histórias. "Um diagrama é sobretudo um ícone, um ícone de relações inteligíveis"; "um diagrama - embora possa ter normalmente traços simbolóides, assim como traços de natureza próxima à dos índices, é, não obstante, acima de tudo, um ícone das formas de relações na constituição de seu objeto" (PEIRCE 1895, apud CAMPOS, 1994, p. 81). É desse modo que parece funcionar a sequência de cantos que perfazem um ritual yãmîyxop maxakali. Ao se emitirem alguns cantos determinados, é possível reconstruir toda a narrativa correspondente mentalmente. E, a partir daí, representar, por meio de outros materiais, os elementos que compõem a encenação do ritual, por meio de outras linguagens, para além da língua e do canto: figurino, alimento, coreografia, etc.

Tal procedimento é o mesmo do método ideogrâmico que subjaz à composição dos cantos yãmîy em si, como demostrado também em "Ideograma e pensamento selvagem: a arte e a ciência do yãmîy maxakali" (BICALHO, 2007a), em que se analisa a relação entre a arte maxakali e sua ciência, imbricadas no método de seus espíritos yãmîy, ao mesmo tempo produtores de arte e de conhecimento. Assim, "o que temos no yãmîy é o que é chamado de 'montagem de atributos'” (p. 179). Ou, como escreve Géfin (1982), relativamente ao método poético do norte-americano Ezra Pound: "a base mesma do método ideogrâmico, a 'afinidade intuitiva pela descrição de particularidades' de Pound" (p. 5). ${ }^{3}$ Ou seja, se por um lado o canto se configura enquanto diagrama do tema que aborda (um animal ou um espírito, por exemplo), por outro lado, a sequência de cantos se configura enquanto diagrama da narrativa. Para tanto, demanda-se a realização do ritual, evento que convoca os cantos em sequência determinada.

BICALHO, Charles Antônio de Paula. o "cinema" cantado dos Maxakali PóS:Revista do Programa de Pós-graduação em Artes da EBA/UFMG. v.9, n. 18: nov.2019

Disponível em < https://eba.ufmg.br/revistapos $>$

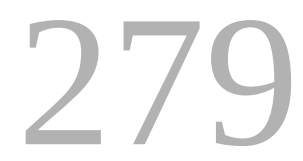


Sobre a cronofotografia de E. J. Marey (fundamento teórico do cinema moderno), Virilio (2015) diz que ela faz "desaparecer o corpo, em prol de uma combinação instantânea de dados" (p. 58). Estamos de fato diante da noção de diagrama semiótico; ou seja, uma reunião de dados estruturais fundamentais de um objeto, desprezando o que for supérfluo, para compor sua imagem. O que seria em essência a "estética da desaparição", sugerida pelo título da obra do autor. Tal concepção vai ao encontro do método ideogrâmico, que nos dá uma imagem de traços primordiais da coisa representada ou mencionada ("montagem de atributos" ou "descrição de particularidades"), seja em nível micro (na composição dos cantos), seja em nível macro (na recomposição cantada das narrativas nos rituais), no caso maxakali.

Consequentemente, continua Virilio, a ilusão visual do cinema, que "destrói a percepção consciente do espectador", provocaria uma fixação do olhar na coisa, "que não pode durar muito mais que um segundo sem o sério risco de ver o sujeito cair em transe hipnótico ou em algum estado patológico análogo" (WOLF apud VIRILIO, 2015, p. 58). Nesse caso, o cinema cantado maxakali provocaria semelhante "fixação" do olhar na coisa; por mais de um segundo, no entanto; levando, portanto, ao transe ritualístico. Se Marey, como quer Virilio, "reduz o movimento do ser vivo a alguns sinais luminescentes" (VIRILIO, 2015, p. 59), também o fazem os Maxakali com seus cantos, igualmente proporcionando aos participantes de seus rituais yãmîyxop "penetrar num universo nunca visto, onde nenhuma forma nos é dada" (Ibidem.), muito provavelmente porque a forma privilegiada aí é aquela que se transforma: a metamorfose (BICALHO, 2013). A cronofotografia e o diagrama, ambos uma espécie de duplo do real, nos revelariam outros aspectos da visão ou da imagem que fazemos do mundo, assim como um ritual pode ser a recriação de aspectos deste mundo.

\section{Considerações finais}

Diante do que foi aqui exposto, esperamos ter demonstrado como a produção do filme Konãgxeka: o Dilúvio Maxakali (2016) dialoga com o ritual maxakali e a sequência de cantos que o perfazem. O conhecimento da língua maxakali e de suas expressões literárias, e da

BICALHO, Charles Antônio de Paula. o "cinema" cantado dos Maxakali

PóS:Revista do Programa de Pós-graduação em Artes da EBA/UFMG. v.9, n.18: nov.2019

Disponível em < https://eba.ufmg.br/revistapos $>$ 
natureza do ritual yãmîyxop e de sua estrutura é de grande auxílio em todo o processo de produção audiovisual com os Maxakali ou Tikmû'ûn. O diálogo com a tradição ritualística, de base oral, mostra-se fundamental para a concepção da obra cinematográfica maxakali.

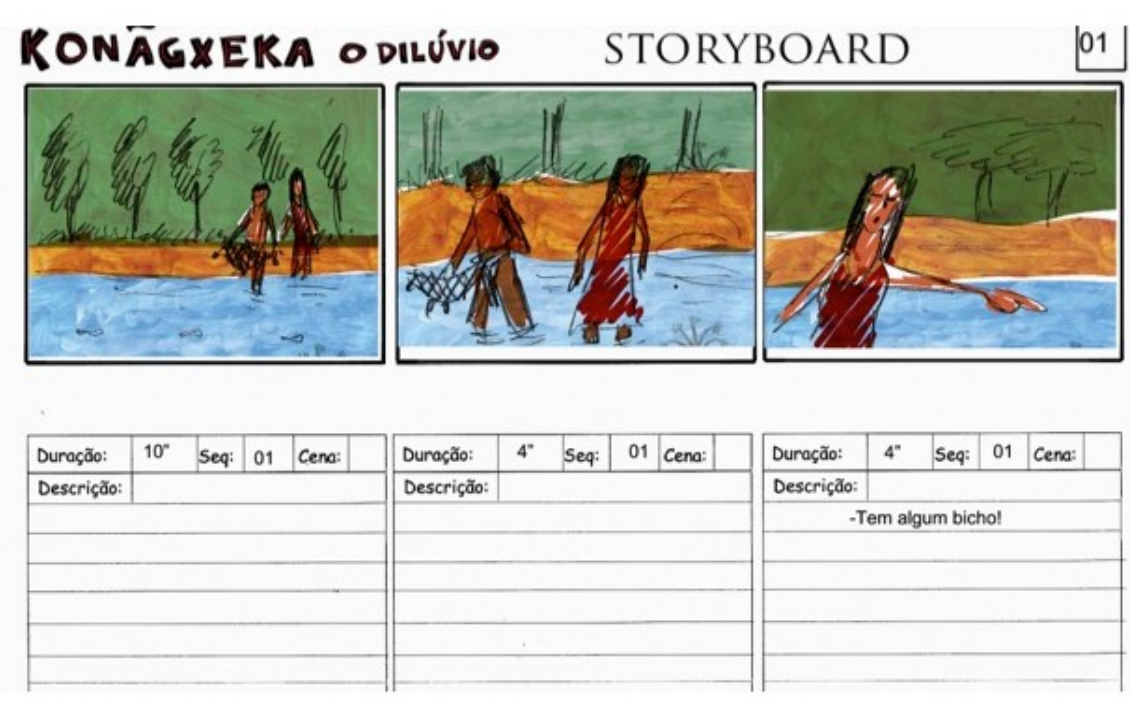

Figura 6 - Storyboard de Konãgxeka: o Dilúvio Maxakali - 2016 Fonte: Pajé Filmes, 2016.

Uma vez articulando seus cantos, de modo deliberado, para referenciar suas narrativas, os Maxakali se tornam autores de um discurso com forte apelo visual e sequencial, baseado em palavras cantadas. Emitir tais cantos específicos, relativos a narrativas determinadas, respeitando combinações ordenadas, configuraria uma linguagem específica, diferente de outros tipos de emissão de cantos ritualísticos que não necessariamente remetem a alguma narrativa. Se para Metz (2014), o cinema "pode ser considerado como uma linguagem, na medida em que ordena elementos significativos no seio de combinações reguladas" (p. 127), o modo de ordenação dos cantos maxakalis sugeriria algo da lógica do mecanismo da linguagem cinematográfica.

Desde a criação do roteiro, a concepção dos personagens, passando pela criação do storyboard e a direção de arte, bem como de outros aspectos, desde a pré-produção até a pósprodução, conhecer a tradição mais profunda, expressa nos rituais yãmîyxop dos Maxakali, nos ajuda a perceber que os princípios da arte cinematográfica já podem estar dados em

BICALHO, Charles Antônio de Paula. o "cinema" cantado dos Maxakali PóS:Revista do Programa de Pós-graduação em Artes da EBA/UFMG. v.9, n.18: nov.2019 Disponível em < https://eba.ufmg.br/revistapos $>$ 
todas as culturas, uma vez que a busca pela representação, não só da imagem, mas também de sua sequência e movimento, podem já estar presentes nas expressões mitológicas e ritualísticas.

Thomas Edison vislumbrou uma função didática para o cinema quando disse que futuramente as aulas seriam dadas usando o seu mecanismo de projeção de imagens. Já Bergson, segundo Virilio (2015, p. 47) afirmara: "O mecanismo do nosso conhecimento usual é de natureza cinematográfica" (BERGSON apud VIRILIO, 2015, p. 47). De fato, ao tomarmos o ritual maxakali na perspectiva aqui proposta - a de um princípio cinematográfico -, tendo o ritual yãmîyxop como um complexo mecanismo de conhecimentos e de linguagens, poderíamos corroborar a afirmação de Edison. Os rituais yãmîyxop, com seus cantos yãmîy projetando imagens mentais por meio do canto, são fonte de informação e conhecimento, de socialização e de arte. 


\section{REFERÊNCIAS}

ALVARES, M. M. Yãmîy, os espíritos do canto: a construção da pessoa na sociedade Maxakali. Mestrado em Antropologia Social. Instituto de Filosofia e Ciências Humanas da Universidade Estadual de Campinas, Campinas, 1986.

BICALHO, Charles. A imagem na arte verbal Maxakali: aspectos de uma poética de pajelança. Revista Galáxia, PUC-SP, p. 88-109, 2018.

BICALHO, Charles. Metamorfose na literatura Maxakali. Em Tese - revista do Programa de Pós-Graduação em Estudos Literários (Pós-Lit), FALE-UFMG, Belo Horizonte, v. 19, n.13, p. 11-23, 2013.

BICALHO, Charles. Koxuk - a imagem do yãmîy na poética maxakali. Orientadora: Profa. Dra. Maria Inês de Almeida. 2010. 229 f. Tese. (Doutorado em Estudos Literários) Faculade de Letras, Universidade Federal de Minas Gerais, Belo Horizonte, 2010.

BICALHO, Charles. Ideograma e pensamento selvagem: a arte e a ciência do yãmîy maxakali. Revista Gragoatá, Universidade Federal Fluminense, v. 12, n. 23, p. 169-187, 2007a.

BICALHO, Charles. Yãmîy maxakali: um gênero nativo de poesia. Revista Aletria, Faculdade de Letras da UFMG, v. 16, p. 119-132, 2007b.

CAMPOS, Haroldo de. (org.). Ideograma - lógica, poesia, linguagem. 3 ed. São Paulo: Edusp, 1994.

EISENSTEIN, Serguei. A forma do filme. Tradução: Teresa Ottoni. Rio de Janeiro: Jorge Zahar Editor, 2002.

GÉFIN, Laszlo K. Ideogram - history of a poetic method. Austin: U. of Texas Press, 1982.

KONÃGXEKA: o Dilúvio Maxakali. Direção e roteiro: Charles Bicalho e Isael Maxakali. Brasil: Pajé Filmes, 2016. Disponível em: https://www.youtube.com/watch?v=_XKNdLtJZGs Acessado em: 18 de outubro de 2019.

LÉVI-STRAUSS, C. Antropologia estrutural. 4. ed. Rio de Janeiro: Tempo Brasileiro, 1991. MACHADO, Arlindo. Pré-cinemas e pós-cinemas. Campinas, São Paulo: Papirus, 1997. MAXAKALI, Povo. Yãmiy xop xohi yõg tappet - Livro de cantos rituais Maxakali. Belo Horizonte: Secretaria Estadual de Educação de Minas Gerais, 2004.

METZ, Christian. A significação no cinema. Tradução de Jean-Claude Bernardet. São Paulo: Perspectiva, 2014.

PEIRCE, C. S. Semiótica. 3 ed. Tradução de José Teixeira Coelho Neto. São Paulo: Perspectiva, 2005.

BICALHO, Charles Antônio de Paula. o "cinema" cantado dos Maxakali PóS:Revista do Programa de Pós-graduação em Artes da EBA/UFMG. v.9, n.18: nov.2019 Disponível em < https://eba.ufmg.br/revistapos $>$ 
POPOVICH, A. Harold. Maxakali Supernaturalism. Dallas, Texas: Summer Institute of Linguistics, 1976.

RANCIÈRE, Jacques. 0 destino das imagens. Tradução de Mônica Costa Netto. Rio de Janeiro: Contraponto, 2012.

TUGNY, Rosangela Pereira. Reverberações entre cantos e corpos na escrita Tikmû'ûn. Revista Transcultural de Música, n. 15, 2011. Disponível em:

https://www.sibetrans.com/trans/public/docs/trans_15_18_Pereira.pdf. Acesso em: dez. 2018.

VIRILIO, Paul. Estética da desaparição. Tradução: Vera Ribeiro. Rio de Janeiro: Contraponto, 2015.

VIVEIROS DE CASTRO, Eduardo. Araweté, os deuses canibais. Rio de Janeiro: Jorge Zahar, 1986.

BICALHO, Charles Antônio de Paula. o "cinema" cantado dos Maxakali PóS:Revista do Programa de Pós-graduação em Artes da EBA/UFMG. v.9, n.18: nov.2019 Disponível em < https://eba.ufmg.br/revistapos $>$ 


\section{NOTAS}

1 Palavra maxakali com a qual os índios se autodenominam. Seu significado aproximado é "humanidade".

2 Pode-se assistir ao filme no canal da produtora Pajé Filmes no YouTube no link: https://www.youtube.com/watch?v= XKNdLtJZGs

3 "the very basis of the ideogramic method, Pound's 'intuitive affinity for description by particulars"' 